\title{
Experimental investigation of the spreading of viscoplastic fluids on inclined planes
}

\author{
S. Cochard ${ }^{\mathrm{a}, *}$, C. Ancey ${ }^{\mathrm{b}}$ \\ a Department of Mathematics, University of British Columbia, Vancouver, Canada \\ b School of Architecture, Civil and Environmental Engineering, École Polytechnique Fédérale de Lausanne, 1015 Lausanne, Switzerland
}

\section{A R T I C L E I N F O}

\section{Article history:}

Received 11 April 2008

Received in revised form 28 July 2008

Accepted 14 August 2008

\section{Keywords:}

Viscoplastic fluids

Dam breaks

Experimental results

\begin{abstract}
A B S T R A C T
We report experimental results related to the dam-break problem for viscoplastic fluids. Using image processing techniques, we were able to accurately reconstruct the free-surface evolution of fixed volumes of fluid suddenly released a plane. We used Carbopol Ultrez 10 as a viscoplastic material; its rheological behavior was closely approximated by a Herschel-Bulkley model for a fairly wide range of shear-rates. Varying the Carbopol concentration allowed us to change the yield stress and bulk viscosity. The yield stress ranged from 78 to $109 \mathrm{~Pa}$, producing Bingham numbers in the 0.07-0.35 range. We investigated the behavior of a 43-kg mass released on a plane, whose inclination ranged from $0^{\circ}$ to $18^{\circ}$. For each run, we observed that the behavior was nearly the same: at short times, the mass accelerated vigorously on gate opening and very quickly reached a nearly constant velocity. At time $t=1 \mathrm{~s}$, independently of plane inclination and yield stress, the mass reached a near-equilibrium regime, where the front position varied as a power function of time over several decades. We did not observe any run-out phase, during which the mass would have gradually come to a halt. The similarity in the flow behavior made it possible to derive an empirical scaling for the front position in the form $x_{\mathrm{f}}=t^{0.275(\sin \alpha)^{1 / 3}}(\sin \alpha)^{5 / 4}$, where $\alpha$ and $t$ denote plane inclination and time, respectively, and which holds for sloping beds $(\alpha>0)$.
\end{abstract}

(C) 2008 Elsevier B.V. All rights reserved.

\section{Introduction}

Numerous applications in industrial processes and nature involve the release of a finite volume of viscoplastic materials onto a surface. In civil engineering, the slump test is commonly used to determine the flow features of concrete and has given rise to abundant literature on empirical yield stress measurement [1-6]. A similar test, referred to as the Bostwick test, is widely used in the food industry to characterize the consistency of food products. This test has also attracted attention over recent years, mostly in relation to interpretation of test results [7-10]. Geophysical flows offer many examples of finite volumes of plastic materials spreading on a slope. Typical examples include snow avalanches and debris flows $[11,12]$ as well as volcanic lava [13].

While much of the earlier work has focused on time-dependent flows of viscous fluids over a rigid boundary [14-17], a growing attention has been paid to the corresponding problem with viscoplastic fluids from the theoretical point of view [18-29]. On rare occasions, exact or asymptotic analytical solutions to the governing equations can be worked out $[10,21,30-34]$, but

\footnotetext{
* Corresponding author.

E-mail address: steve.cochard@a3.epfl.ch (S. Cochard).
}

most of the time, solutions must be computed numerically using flow-depth averaged equations of motion (the equivalent of the shallow-water equations in hydraulics) [35-37], nonlinear diffusion equations when inertial terms are negligible $[19,21]$, or the full set of equations of motion (using a finite-element approach or smooth-particle-hydrodynamics techniques). Surprisingly, despite the substantial interest in the spreading of viscoplastic fluids, there have been to date very few experimental investigations reporting the flow behavior of a finite volume of viscoplastic fluids down a surface. Debiane [38] tracked the front position and flow-depth profiles of fixed volumes of Carbopol released down a 3-m long, $30-\mathrm{cm}$ wide flume. The flow-depth profile was estimated using ultrasonic devices while the position of the front was monitored using a high speed camera mounted on a mobile carriage. Siviglia and Cantelli [37] investigated the effect of bed curvature on flow dynamics. Chanson et al. [32] studied the dam-break problem with thixotropic viscoplastic fluids using a 2-m long, 0.34-m wide flume inclined at $15^{\circ}$. The free-surface elevation was measured using a CCD camera and a series of laser sheets.

In this paper, we report experimental results of dam-break flows involving fixed volumes of viscoplastic materials. The dam-break experiment consists of the sudden release of a finite volume of material down a slope or onto a horizontal surface. Initially, the fluid is placed in a reservoir at the top of the plane, as sketched 


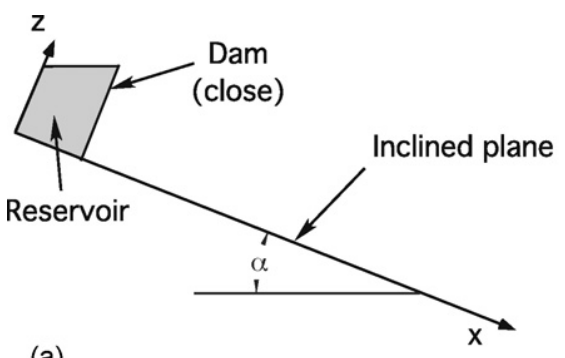

(a)

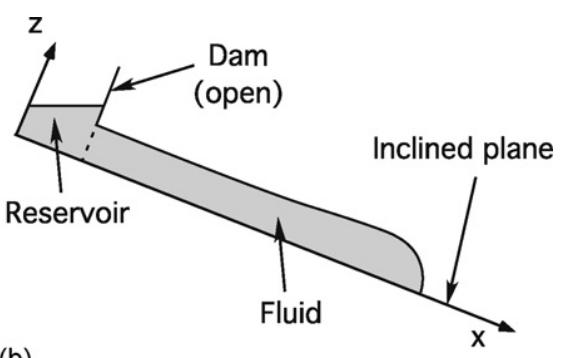

(b)

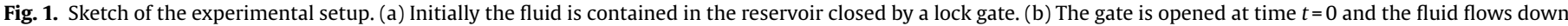
the inclined plane.

in Fig. 1. It is then unleashed by lifting the lock gate and flows, driven by gravitational forces. The initial conditions (volume of fluid, rheological features, density) and the boundary conditions (slope angle, surface roughness, topography) can easily be altered and controlled, which makes this test very appropriate to understand time-dependent flows. In particular, this setting has been used as a benchmark for testing theory against data for inviscid and Newtonian fluids [ $15,16,39]$; in that case, experimentalists were satisfied with the measurement of the front position over time since on the one hand, this position can be accurately monitored experimentally and on the other hand, one can predict the front evolution using similarity theory. The situation is markedly different for non-Newtonian fluids, for which one is interested in both the front position and free-surface shape, which is a delicate experimental task. To take up this challenge, we built a new imaging system, which makes it possible to accurately reconstruct the free surface of an avalanching mass of fluid. In Section 2.1, we outline the techniques developed for this purpose; the interested reader is referred to an earlier publication for further information [40]. Another substantial challenge posed by non-Newtonian fluids lies in the proper characterization and control of rheological properties. An equation such as the Herschel-Bulkley model is an idealization of how a viscoplastic material behaves. In this respect, a number of physical features such as viscoelasticity and thixotropy are not accounted for; furthermore, disturbing effects (e.g., slipping, shear banding) are substantial impediments that may spoil the most careful experiments. Taking a closer look at these issues is thus essential. In Sections 2.2 and 2.3, we describe how the fluid samples were prepared and characterized rheometrically. In Section 2.4, we present the experimental procedure. Great care was brought to ensure accuracy and reproducibility of experiments. Section 3 is devoted to experimental results. There we present the data obtained with the inclined plane; a companion paper [41] includes experimental data related to channelized flows. A few conclusions are drawn in the last section.

\section{Experimental procedure}

\subsection{Experimental setup}

To investigate avalanching masses of fluid, we built an experimental setup made up of a high-rigidity metal frame supporting a reservoir, a 6-mm-thick aluminium plate, and a horizontal run-out zone. This full facility was $5.5 \mathrm{~m}$ long, $1.8 \mathrm{~m}$ wide, and $3.5 \mathrm{~m}$ high. The plate could be inclined from $0^{\circ}$ to $45^{\circ}$ (see Fig. 2 ). Its position was accurately controlled using a digital inclinometer with a resolution of $0.1^{\circ}$. Since Carbopol slipped on aluminium, we painted the aluminum plate with Krautol Zink-und-Alugrund-3363 paint (provided by Selma AG, Schwerzenbach, Switzerland).

The reservoir was positioned at the top of the inclined plane behind the lock gate. The reservoir was $51 \mathrm{~cm}$ long and $30 \mathrm{~cm}$ wide.

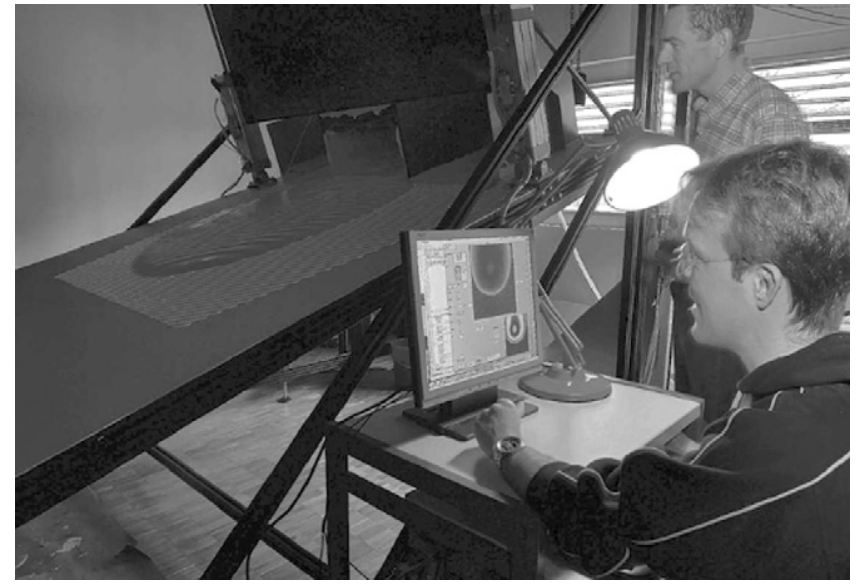

Fig. 2. View of the inclined plane during a test with Carpobol. Courtesy of C. Blaser.

The maximum capacity of the reservoir was $120 \mathrm{~kg}$. The dam wall was composed of a $1.6 \mathrm{~m} \times 0.8 \mathrm{~m}$ ultralight carbon plate (which was 4-cm-thick). Two pneumatic jacks opened the sluice gate to the desired aperture within $0.8 \mathrm{~s}$. An ultralight lock gate was needed to reduce gate inertia and plane vibration. The two jacks were quickly raised by injecting pressurized air at $7 \mathrm{MPa}$. Two electromagnetic sensors were located at the tip of each jack to control its position and start the clock.

To measure the free-surface shape, we developed a novel imaging system, which consisted of a high-speed digital camera (a Basler A202k) coupled to a synchronized micro-mirror projector (a modified z-Snapper provided by ViALUX, Chemnitz, Germany). The camera recorded how regular patterns projected onto the surface were deformed when the free surface moved (see Fig. 3). We developed algorithms to process the image data, determine the spreading rate, and reconstruct whole-field three-dimensional

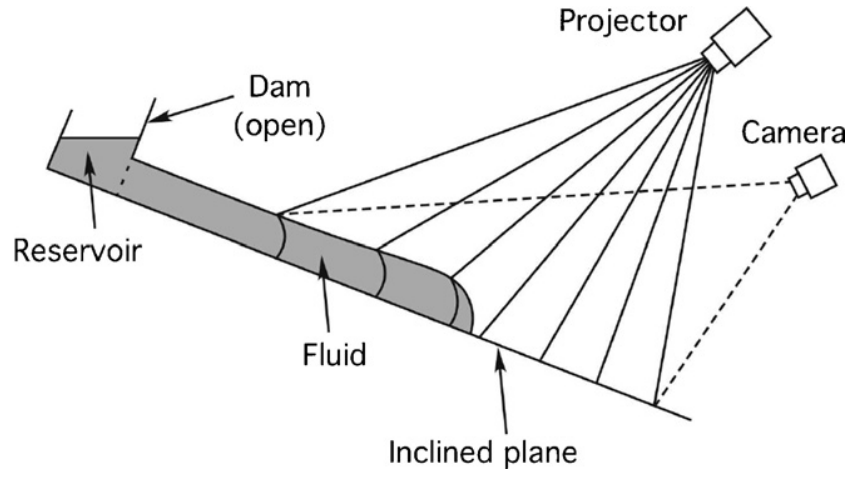

Fig. 3. The Sketch of the experimental setup and the measurement system. 
Table 1

Rheological characteristics and composition of the Carbopol samples used (for a 60-kg mass)

\begin{tabular}{|c|c|c|c|c|}
\hline & \multicolumn{4}{|l|}{ Concentration } \\
\hline & $0.25 \%$ & $0.30 \%$ & $0.35 \%$ & $0.40 \%$ \\
\hline Ultrez 10 [g] & $150.00 \pm 0.05$ & $180.00 \pm 0.05$ & $210.00 \pm 0.05$ & $240.00 \pm 0.05$ \\
\hline $\mathrm{NaOH}[\mathrm{g}]$ & $62.20 \pm 0.05$ & $74.64 \pm 0.05$ & $87.09 \pm 0.05$ & $99.53 \pm 0.05$ \\
\hline $\mathrm{H}_{2} \mathrm{O}[\mathrm{kg}]$ & $59.79 \pm 0.04$ & $59.07 \pm 0.04$ & $58.92 \pm 0.04$ & $58.77 \pm 0.04$ \\
\hline Solution [kg] & $60.00 \pm 0.04$ & $60.00 \pm 0.04$ & $60.00 \pm 0.04$ & $60.00 \pm 0.04$ \\
\hline$\tau_{c}[\mathrm{~Pa}]$ & $78 \pm 1$ & $89 \pm 1$ & $102 \pm 1$ & $109 \pm 1$ \\
\hline$K\left[\mathrm{~Pa} \mathrm{~s}^{-n}\right]$ & $32.1 \pm 2.3$ & $47.68 \pm 1.7$ & $58.91 \pm 1.7$ & $75.84 \pm 1.9$ \\
\hline$n$ & $0.388 \pm 0.023$ & $0.415 \pm 0.021$ & $0.505 \pm 0.027$ & $0.579 \pm 0.033$ \\
\hline
\end{tabular}

shapes of the free surface. The free surface was reconstructed with an accuracy of $1 \mathrm{~mm}$ over a surface of $1.4 \mathrm{~m} \times 1.4 \mathrm{~m}$ at a rate of $45 \mathrm{~Hz}$ (further details of the experimental procedure are provided by [40]).

In terms of computation time, for a typical 3-min experiment, the post-processing phase required almost one week on a singleprocessor machine. To reduce computation time, we ran the postprocessing phase on a cluster of two Mac-Pro computers with 8processor cores. Parallel computation reduced processing time to 1 day, which enabled us to conduct more experiments and apply more sophisticated processing algorithms.

\subsection{Fluid}

We used Carbopol Ultrez 10, a viscoplastic stable polymeric gel. This is a carbomer polymeric gel produced by Noveon. Hereafter and unless specified otherwise, Carbopol refers to Carbopol Ultrez 10. Carbopol was used at four different concentrations. Table 1 summarizes the concentration of the different components used. We also report the rheological parameters of a Herschel-Bulkley equation fit to the rheometrical data (see Section 2.3). Anhydrous NaOH Pellets RPE-ACS-ISO was used to neutralize the Carbopol solution to a $\mathrm{pH}$ of 7 . The solvent was demineralized water. A full description of the preparation procedure is described in [42].

\subsection{Rheometry}

The flow curve of the viscoplastic gel was determined using a Bohlin CVOR rheometer equipped with a Couette cell (see Fig. 4). The inner and the outer cylinder cell walls were covered with waterproof sandpaper 180 to reduce slip. The dimensions of the cell and the rotating bob are reported in Fig. 4.

We first determined the yield stress using a creep test. The sample was sheared under constant shear-stress for 6 min and compliance $J$ was recorded as a function of time $t$. We started with a low shear-stress value and we incremented it by 1-Pa steps until the curve $J(t)$ diverged from the previous records. Fig. 5 shows the results of a series of creep tests for a Carbopol sample at the

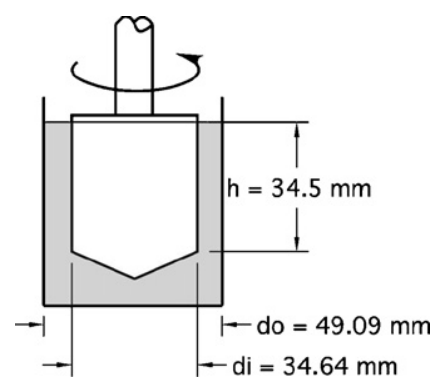

Fig. 4. The Couette geometry used in our experiments. concentration of $0.40 \%$ (only every second curve is presented for clarity).

In 1985, Barnes and Walters [43] came up with a provocative article in which they concluded that the yield stress is a myth and does not exist. Coussot et al. [44] provided evidence for an interplay between yield stress and thixotropy. Møller et al. [45] concluded that yield stress and thixotropy of a fluid have the same physical origin. The measurement of the yield stress not only depends on the duration of the experiment, but also on the history of the fluid deformation. In 2007, Piau [46] measured, with MRI-rheometery technique, and compared results for different concentration of Carbopol 940 and 980 at very low shear-rate and found, instead of a yield stress, two Newtonian plateaus. Even if in the yield stress has been questioned as a physical property, the concept of a yield stress still remains very useful for a wide range of applications. In this paper, we used a 6 min creep test to define the yield stress.

We then determined the flow curve, i.e., the shear-stress/shearrate relation. To that end, we used a standard technique, which involved imposing a step-like ramp of stress and recording the resulting deformation until equilibrium was reached (i.e. shear-rate was constant). The initial stress was $10 \mathrm{~Pa}$ higher than the yield stress and was then progressively increased by 2-Pa increments. The shear-stress range covered one decade. From the raw data, we determined the flow curve:

- we solved the Couette inverse problem using Tikhonov regularization techniques; and then

- we adjusted an empirical equation (the Herschel-Bulkley equation) on the data.

In the Couette inverse problem, we have to retrieve the shearstress/shear-rate relation $\tau(\dot{\gamma})$ from torque/rotational-velocity measurements $\omega(T)$. These quantities are related to each other by

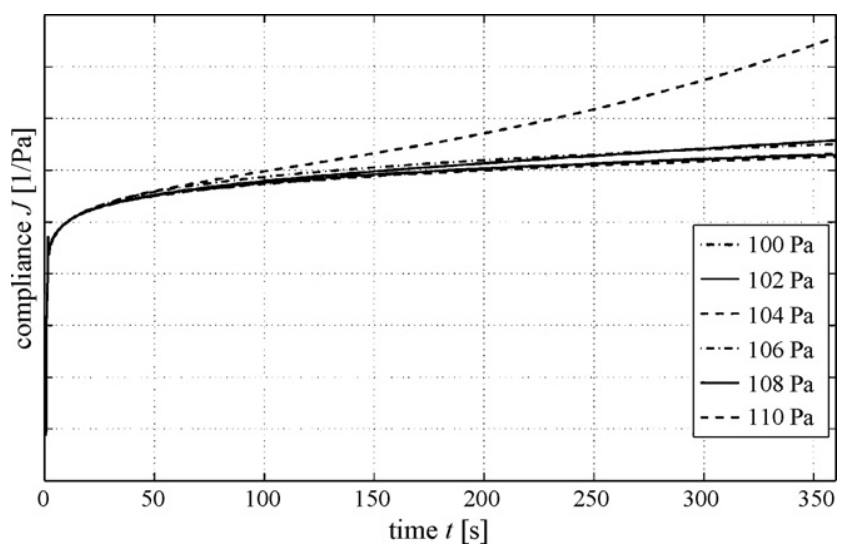

Fig. 5. Creep test of Carbopol Ultrez 10 at a $0.4 \%$ concentration. The yield stress was in the $109 \pm 1$ Pa range. 


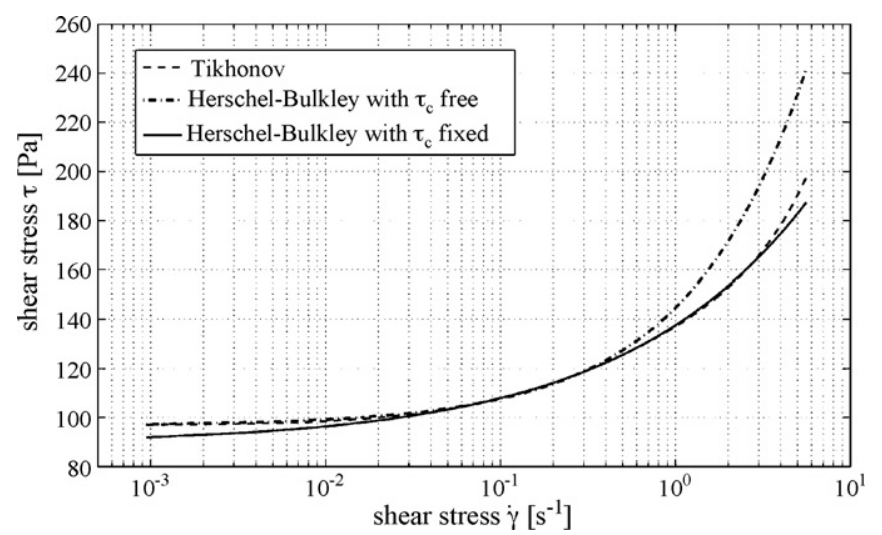

Fig. 6. Herschel-Bulkley model for a sample of Carbopol at a concentration of $0.30 \%$.

the Couette equation $[47,48]$

$\omega(\tau)=(A \dot{\gamma})(\tau)=\frac{1}{2} \int_{\beta \tau}^{\tau} \frac{\dot{\gamma}(S)}{S} \mathrm{~d} S$,

where $\beta=d_{\mathrm{i}} / d_{\mathrm{o}}$ is the ratio of the inner to outer cylinder diameters, $A$ the integral operator, and $S=\tau\left(d_{\mathrm{i}} / 2 r\right)^{2}$ represents the distribution of shear-stress across the cell gap ( $r$ denotes the radial distance from the inner cylinder). The shear-stress is directly derived from the torque $T$ using $\tau=2 M /\left(\pi d_{\mathrm{i}}^{2} h\right)$ with $h$ the inner cylinder height. Tikhonov regularization consists in recovering shear-rate $\dot{\gamma}$ from rotational velocity measurement $\omega(T)$ using a least-square approach: instead of solving $\omega=A \dot{\gamma}$, one minimizes the residual $\|\omega-A \dot{\gamma}\|$, usually subject to an additional constraint on the norm of $\|\dot{\gamma}\|$ or its derivative to control the smoothness of the solution.

To describe the rheological behavior of Carbopol, we used the Herschel-Bulkley model, whose expression for a simple-shear flow is

$\tau=\tau_{\mathrm{c}}+K \dot{\gamma}^{n}$,

with $\tau_{\mathrm{c}}$ the yield stress, $K$ the consistency, and $n$ an index. We determined the value of these parameters from rheometrical experiments as follows: $\tau_{\mathrm{c}}$ was set to the value determined by the creep test while $K$ and $n$ were computed using a least-square approach. Eq. (2) can be integrated across the gap to provide the theoretical variation in the torque as a function of the rotational velocity. The resulting equation can then be used to fit the raw data and derive $\tau_{\mathrm{c}}, n$, and $K$ values.

Fig. 6 gives an example of results obtained for Carbopol Ultrez 10 at a concentration of $0.30 \%$. The dashed line represents the results from the Couette rheometer using Tikhonov's method. The dashand-dot line is the best-fit line when the parameters $\tau_{\mathrm{c}}, K$, and $n$ were free: $\tau=96.7+47.9 \dot{\gamma}^{0.54}$. We also considered that the yieldstress value was measured independently with the creep test (see above) and we sought $K$ and $n$ using the least-square method; in that case we obtained $\tau=90.0+47.6 \dot{\gamma}^{0.43}$ (solid line in Fig. 6). As seen on this log-linear plot, there is little difference between the three curves for $\dot{\gamma}$ ranging from 0.02 to $0.5 \mathrm{~s}^{-1}$. Small deviations can be observed in the low-shear-rate regime $\left(\dot{\gamma}<0.1 \mathrm{~s}^{-1}\right)$, but much larger differences are seen for large shear-rate values $(\dot{\gamma}>$ $1 \mathrm{~s}^{-1}$ ), which shows how important it is to select an appropriate adjustment procedure.

Carbopol exhibits little thixotropy. In our case, to evaluate the thixotropy influence on the rheological behavior, we ran standard hysteresis loop tests. These tests are known to be insufficient for fully characterizing thixotropy, but satisfactory when the intent is just to appreciate the influence of thixotropy [49]. We first applied a linear shear-rate ramp (from zero to a maximum value) to our

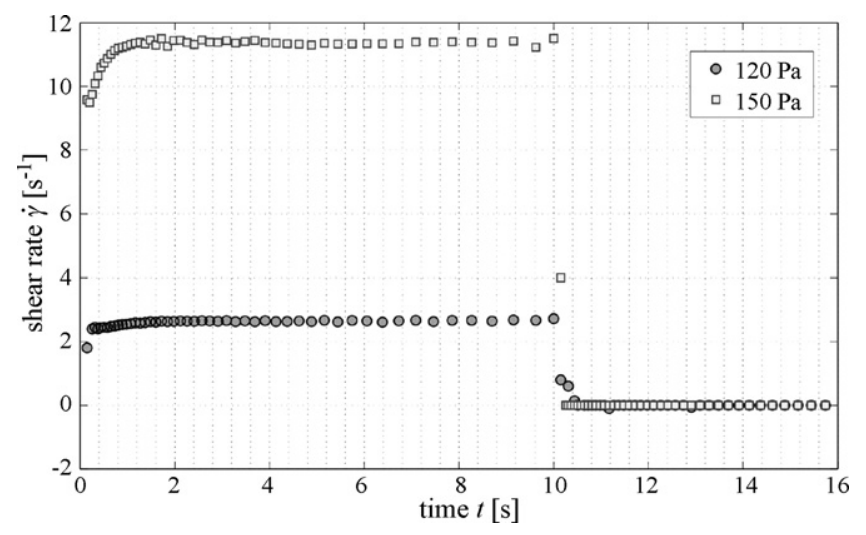

Fig. 7. Creep test and recovery period on a sample of Carbopol with a 40-mm serrated parallel on a sample of Carbopol at a concentration $C$ of $0.30 \%$.

sample, then we decreased the shear-rate while following the same ramp backward. The procedure was repeated several times until a constant loop behavior was produced. The area between the upper and lower curves is a measure of thixotropy. The test was also repeated with 120 and 180-s ramps. The curves are close to each other (within the measurement error) and the loop area is small, leading to the conclusion that our Carbopol samples were weakly thixotropic.

Another test consisted in imposing a 10 -s creep followed by a recovery period. To that end, we used a $40-\mathrm{mm}$ serrated parallelplate geometry to reduce inertia and enhance accuracy. The applied stress was just above the yield stress. The time to reach equilibrium gave an indication of how thixotropic the sample was. Fig. 7 shows a 120- and 150-Pa creep test for a Carbopol sample at the concentration of $0.30 \%$. Equilibrium was reached, for both tests, within approximately $1 \mathrm{~s}$ after stress application and within less than $1 \mathrm{~s}$ after stress removal. This short relaxation time provided further evidence that Carbopol was weakly thixotropic.

Slip can affect rheometrical measurements with Carbopol [50]. Indeed, under some circumstances the Carbopol polymer chains are repelled from the walls owing to repulsion forces arising from various physico-chemical interactions (e.g., electrostatic and steric forces) between the polymer chains and wall. Molecular migration creates a depletion layer, i.e. a very thin layer of water at the wall, causing slip on the macroscopic level. Since slip could seriously affect our measurements, we paid special attention to this issue. Two techniques are classically used to avoid or reduce slip: roughening or coating the walls [51,52]. Another technique involves shearing the material with a vane (a shaft equipped with four or six blades) [51].

Roughening the wall with water resistant sandpaper 180 provided a satisfactory expedient for the Couette cell (provided that both inner and outer cylinders were covered), but not for the parallel-gap geometry (probably because of inaccuracies in the gap measurement). In contrast, coating the cylinder with PVP $\mathrm{K}-90^{\mathrm{TM}}$ high-molecular-weight polyvinyl-pyrrolidone (produced from International Specialty Products and provided by ISP Switzerland AG, Baar, Switzerland) as suggested by Wu et al. [53] gave, in our case, poor results. Not only the flow curves obtained were below the ones obtained with the sandpaper, but they were also fluctuating. A 6-blade vane also proved not to be appropriate. The rotating vane irreversibly fractured the gel and then spun without shearing it.

\subsection{Experimental procedure}

For each run, we proceeded as follows: 


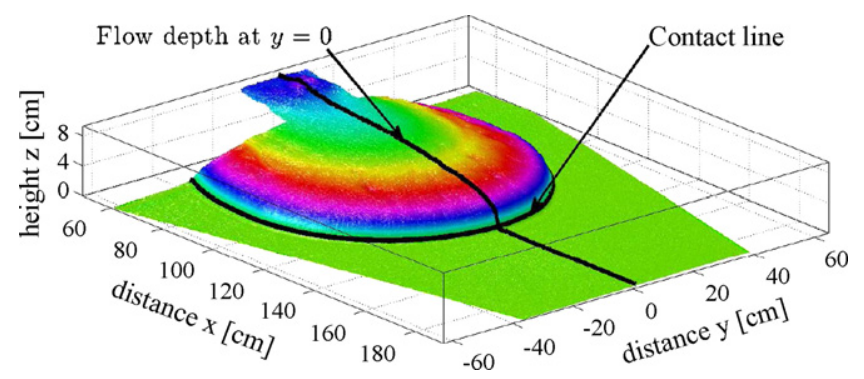

Fig. 8. Three-dimensional view of $43 \mathrm{~kg}$ of Ultrez 10 at a concentration $C$ of $0.25 \%$ down a $6^{\circ}$ slope at time $t=900 \mathrm{~s}$.

(1) The fluid was gently poured into the reservoir, while the plane was kept in the horizontal position. The mass of fluid was fixed to $43 \mathrm{~kg}$.

(2) The upper plane was then inclined at an inclination $\alpha$ to the horizontal. The initial flow-depth at the lock gate ranged from 30 to $36 \mathrm{~cm}$ depending on plane inclination.

(3) The free surface was flattened out by hand. Note that this step is essential to ensuring good reproducibility.

(4) A few minutes before starting the test, we collected a fluid sample and tested it using a Bohlin rheometer to characterize its rheological properties (see Section 2.3).

(5) The acquisition system was turned on.

(6) The clock was set to zero and the acquisition procedure was launched on lifting up the lock gate.

We then reconstructed the three-dimensional shape using the techniques described in Section 2.1. For particular applications, we also extracted the flow-depth profile at the centerline (see Fig. 8) as well as the contour of the mass (referred to as the contact line). The latter was determined by seeking the points where the flow depth dropped below a given threshold (in practice, a value of $0.5 \mathrm{~mm}$ gave good results).

To test out the accuracy, sensitivity and robustness of the experimental apparatus, we repeated many experiments and compared the results. A typical example is provided in Fig. 9, where two different batches of Carbopol prepared with the same protocol were used [42]. The mass and concentration were the same ( $43 \mathrm{~kg}$ and $0.30 \%$, respectively) and the plane inclination was $12^{\circ}$. Fig. 9(a) shows both front positions $x_{\mathrm{f}}$ during the first $60 \mathrm{~s}$ as well as the deviation $\Delta x_{\mathrm{f}}$ between them. In absolute value, $\Delta x_{\mathrm{f}}$ ranged from 2.5 to $6 \mathrm{~mm}$. When scaled with the maximum distance traveled by the mass during the test, the maximum deviation was below $0.4 \%$, which was considered negligible. Fig. 9(b) shows the flow profile at the centerline for both tests. The profiles were similar in both cases since the maximum deviation $\Delta z(x, t)$ between both profiles is on the order of $3 \mathrm{~mm}$. The contact lines are reported in Fig. 10 and again show little difference.

To test our system, we also verified that the surge was symmetric relative to the centerline. As shown in Fig. 10, the flow is symmetric with respect to $y$-axis, with the maximum difference in the $y$ values (for the same elevation) within $5 \mathrm{~mm}$.

Note that in our experiments, the Bingham number

$B i=\frac{\tau_{c}}{K\left(U_{*} / H_{*}\right)^{n}}$

ranged from 0.07 to 0.35 . In the above equation, $H_{*}$ denotes a flowdepth scale (here set to the initial flow depth at the lock gate) and $U_{*}=(\rho g \sin \alpha / K)^{1 / n} H_{*}^{1+1 / n}$ is a velocity scale.
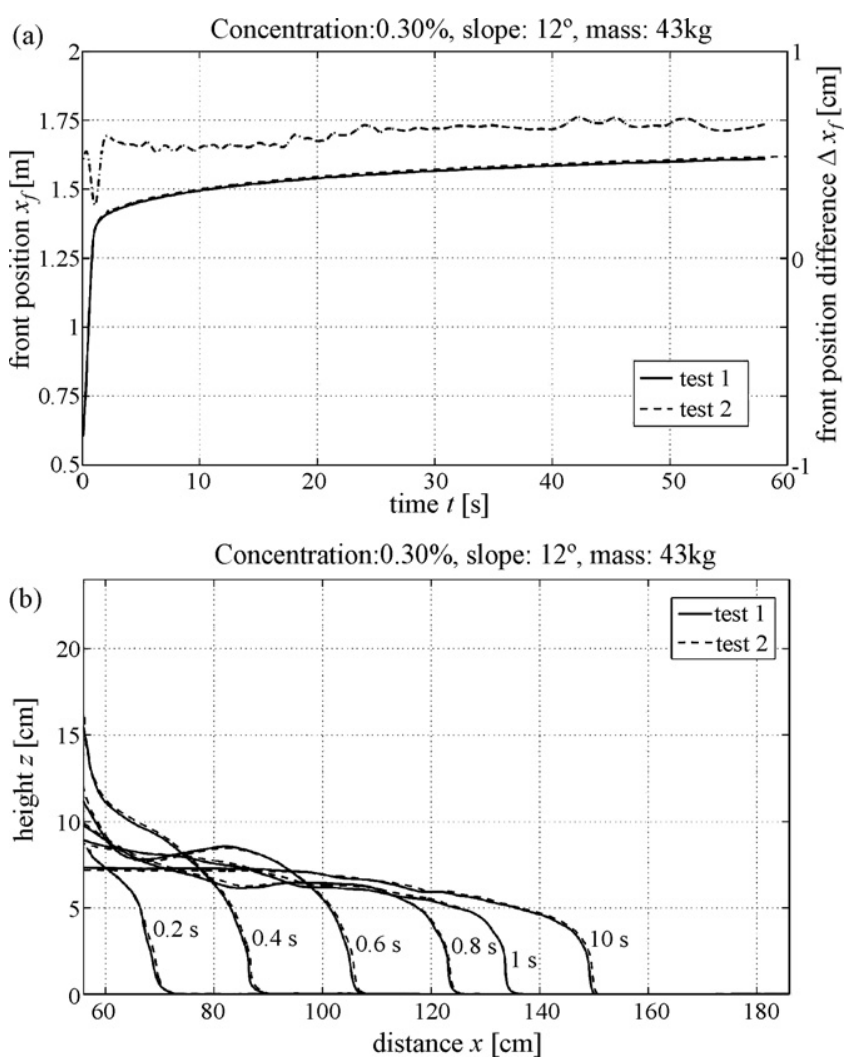

Fig. 9. Results from two similar tests with $m=43 \mathrm{~kg}, \alpha=12^{\circ}$ and $C=0.30 \%$. (a) Front positions $x_{\mathrm{f}}$ (solid and dashed lines) and deviation $\Delta x_{\mathrm{f}}$ (dashed-dotted line). (b) Flow depths $h$.

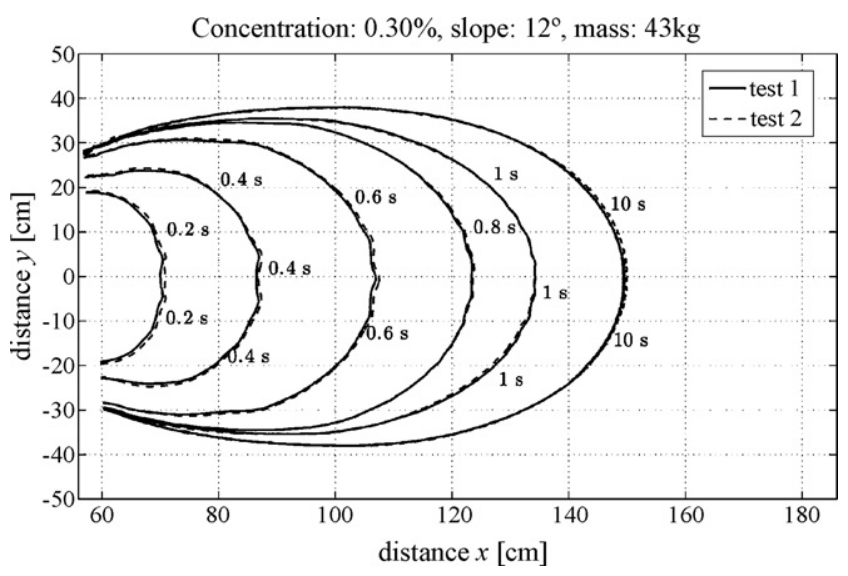

Fig. 10. Position of the contact lines for two tests with $m=43 \mathrm{~kg}, \alpha=12^{\circ}$ and $C=0.30 \%$.

\section{Experimental results}

\subsection{Flow regimes observed}

The spreading of the avalanching mass depended on the fluid rheological parameters $\left(\tau_{\mathrm{c}}, K\right.$, and $n$ ), the plane inclination $(\alpha)$, the reservoir dimensions, and the mass $(m)$. To evaluate the influence of the rheological parameters and plane inclination on propagation, we kept the mass $(43 \mathrm{~kg}$ ) and the reservoir dimensions constant while the concentration and the plane inclination were varied. Sixteen tests were carried out with a $43 \mathrm{~kg}$ mass of Carbopol at concentrations $C=0.25 \%, 0.30 \%, 0.35 \%$, and $0.40 \%$ for plane inclination $\alpha$ of $0^{\circ}, 6^{\circ}, 12^{\circ}$, and $18^{\circ}$. 

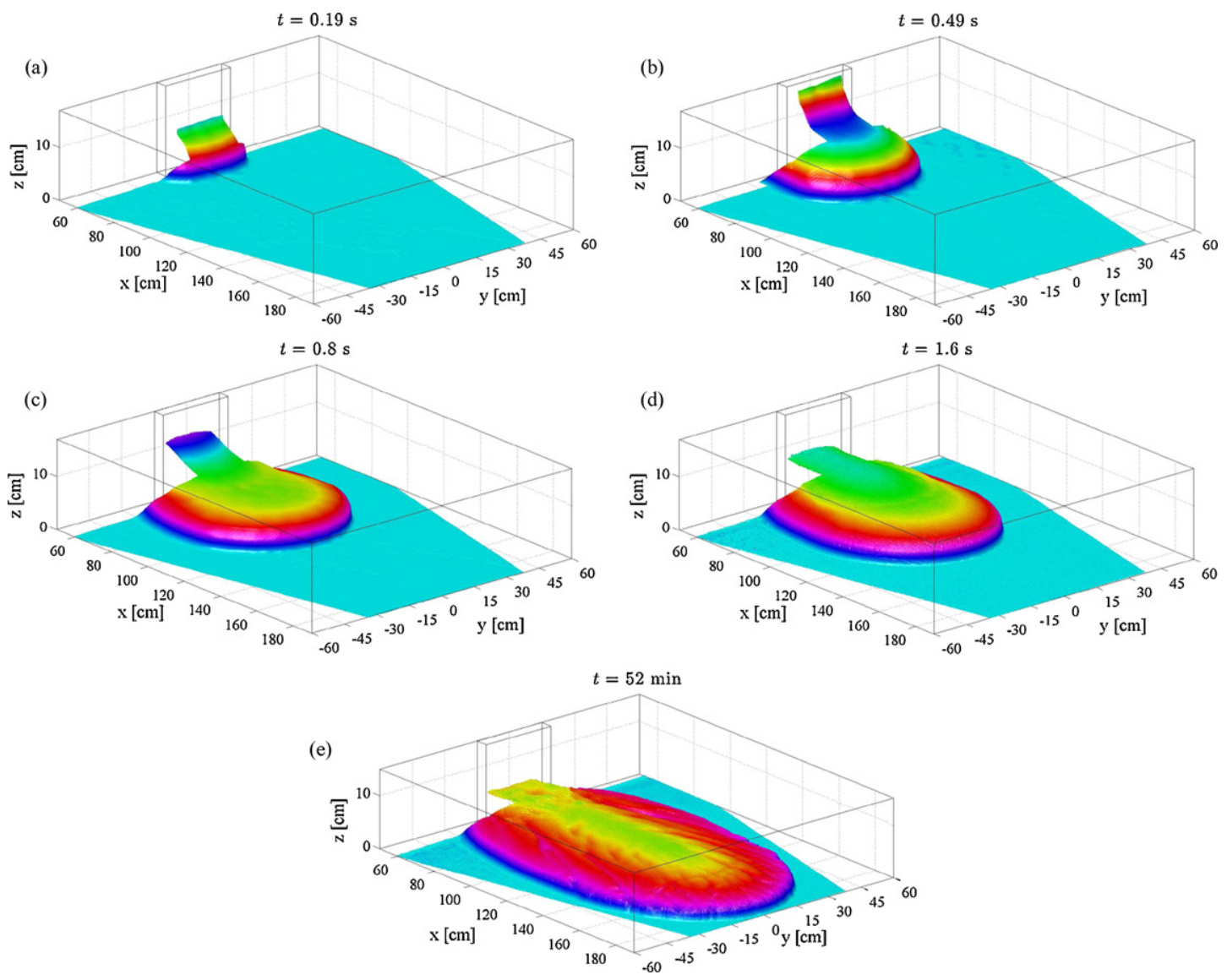

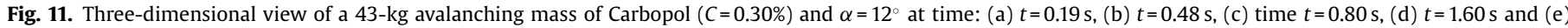
$t=52 \mathrm{~min}$.

We first describe the typical behavior of an avalanching mass. Fig. 11(a)-(e) are snapshots of a typical experiment (here obtained with a $12^{\circ}$ slope and concentration set to $C=0.30 \%$ ). The time variations in the flow-depth profile and front position are reported in Fig. 12 while the contact lines are shown in Fig. 13. We observed the following behavior:

(a) At time $t=0.19 \mathrm{~s}$, the dam gate was being raised. At that time, the effective aperture was $8 \mathrm{~cm}$. The gel was pushed out of the reservoir as a result of hydrostatic pressure. The free surface was nose-shaped. The surge motion was mainly in the $x$-direction.

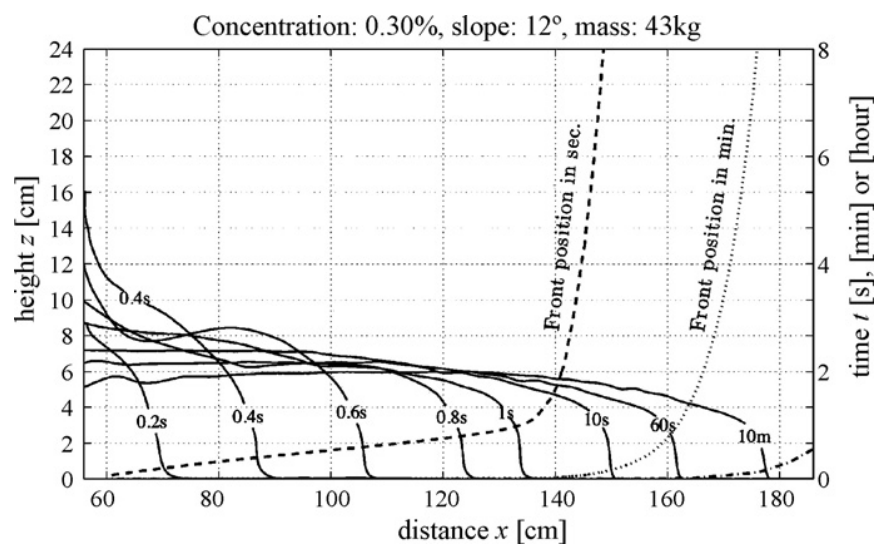

Fig. 12. Surge profile and front position for a 43-kg avalanching mass of Carbopol $\left(C=0.30 \%\right.$ ) down a $12^{\circ}$ inclined plane. (b) At time $t=0.48 \mathrm{~s}$, the dam gate was still being lifted. The aperture was $17 \mathrm{~cm}$, which was still lower than the fluid height in the reservoir (which was about $33 \mathrm{~cm}$ ). The free surface exhibited strong curvature. Since most of the mass was sheared, the mass behaved as a liquid with no visible unsheared zone. The velocity in the $x$-direction was about four times higher than that in the $y$-direction.

(c) At time $t=0.80 \mathrm{~s}$, the gate was fully open. The fluid was still in an inertial regime, i.e. the dynamics was governed by the balance between inertia and pressure-gradient terms. Note that following the gate opening, part of the fluid immediately moved

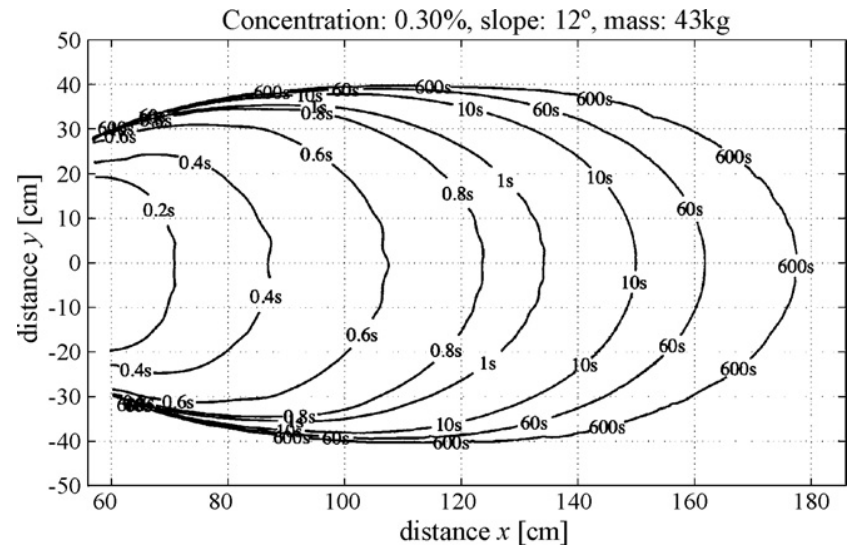

Fig. 13. Contact line for a $43-\mathrm{kg}$ avalanching mass of Carbopol $(C=0.30 \%)$ down a $12^{\circ}$ inclined plane. 
downstream in the form of a forward wave, while a wave propagating upstream separated moving fluid from static fluid upslope. The latter reached the rear end at $t=0.6 \mathrm{~s}$.

(d) At time $t=1.60 \mathrm{~s}$, the gel had slowed down drastically (see Fig. 12). Time variations in the velocity became increasingly smaller, indicating that the gel reached a near-equilibrium regime where the dominant forces were the viscous forces and gravity acceleration. The flow-depth gradient in the streamwise direction was close to zero except for the tip region.

(e) At time $t=52 \mathrm{~min}$, the gel was still moving at $12 \mathrm{~cm} / \mathrm{h}$. Channelization could be observed, as described in Section 3.3 in more detail.
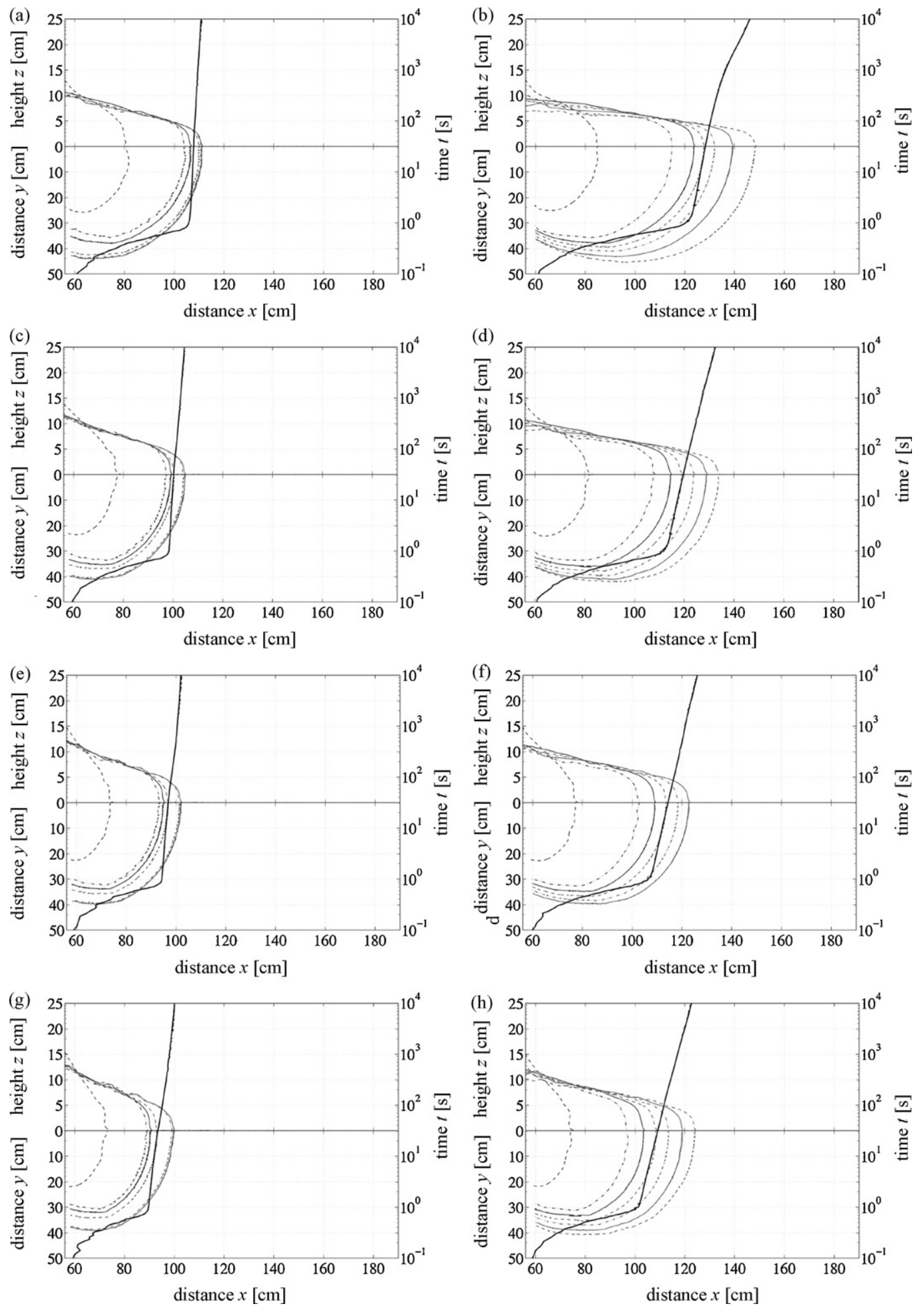

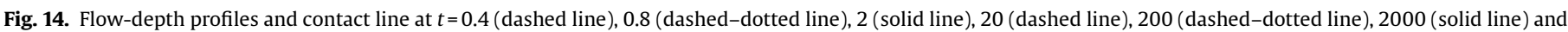

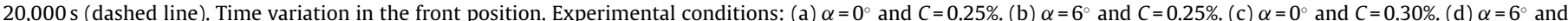
$C=0.30 \%$. (e) $\alpha=0^{\circ}$ and $C=0.35 \%$. (f) $\alpha=6^{\circ}$ and $C=0.35 \%$. (g) $\alpha=0^{\circ}$ and $C=0.40 \%$. (h) $\alpha=6^{\circ}$ and $C=0.40 \%$. 
In brief, we observed two regimes: at the very beginning $(t \leq 1 \mathrm{~s})$, the flow was in an inertial regime; the front velocity was nearly constant. Then, quite abruptly, a pseudo-equilibrium regime occurred, for which the front velocity decayed as a power-law function of time.

The inertial regime depends on the mass of fluids as well as the initial height. The same mass of fluid, in a different reservoir, leading to another initial height would have resulted in a different behavior of the inertial regime.
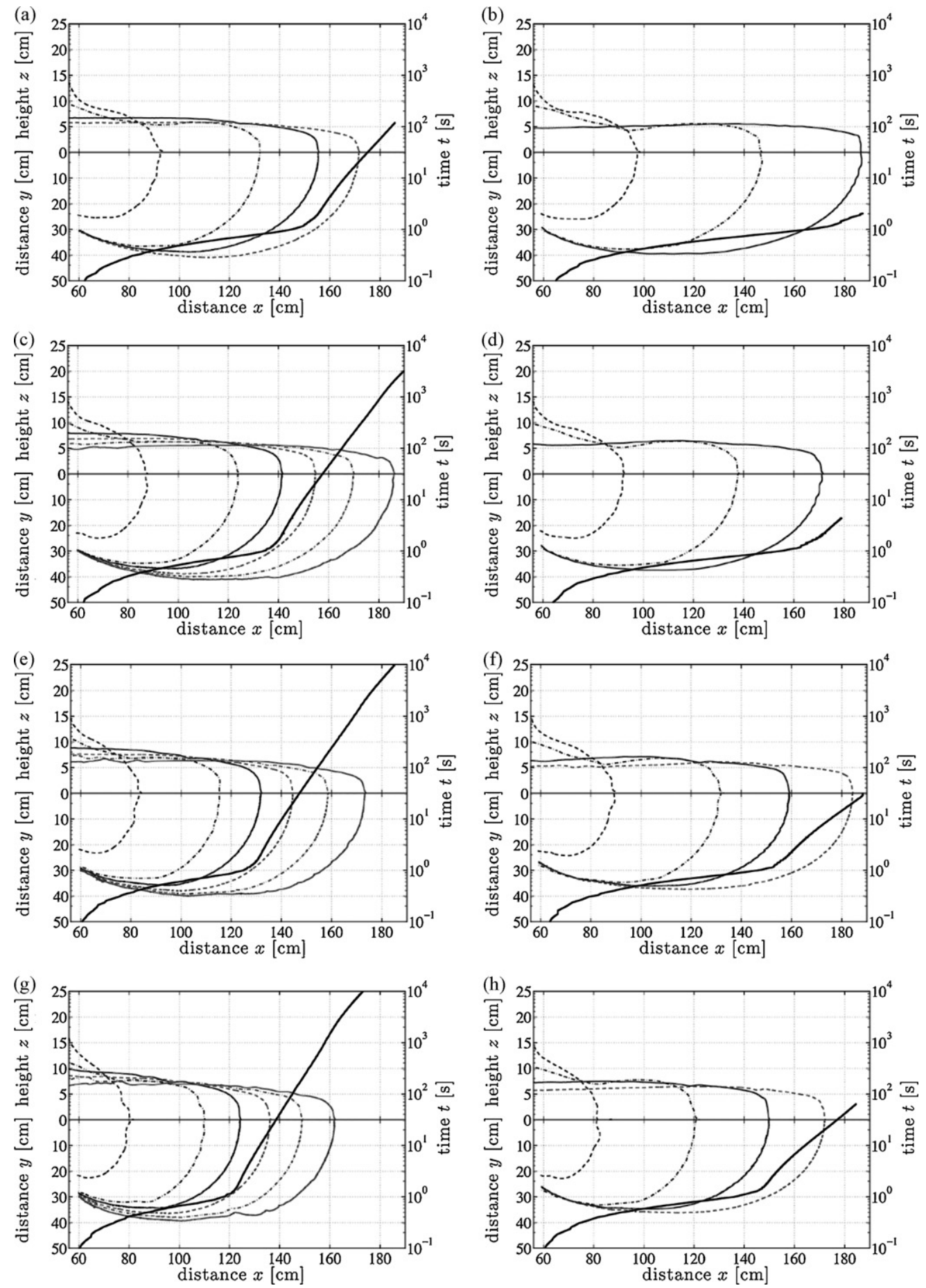

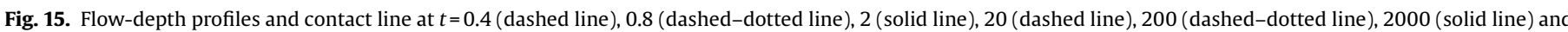

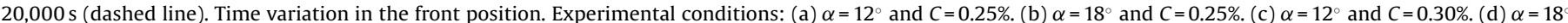
and $C=0.30 \%$. (e) $\alpha=12^{\circ}$ and $C=0.35 \%$. (f) $\alpha=18^{\circ}$ and $C=0.35 \%$. (g) $\alpha=12^{\circ}$ and $C=0.40 \%$. (h) $\alpha=18^{\circ}$ and $C=0.40 \%$. 


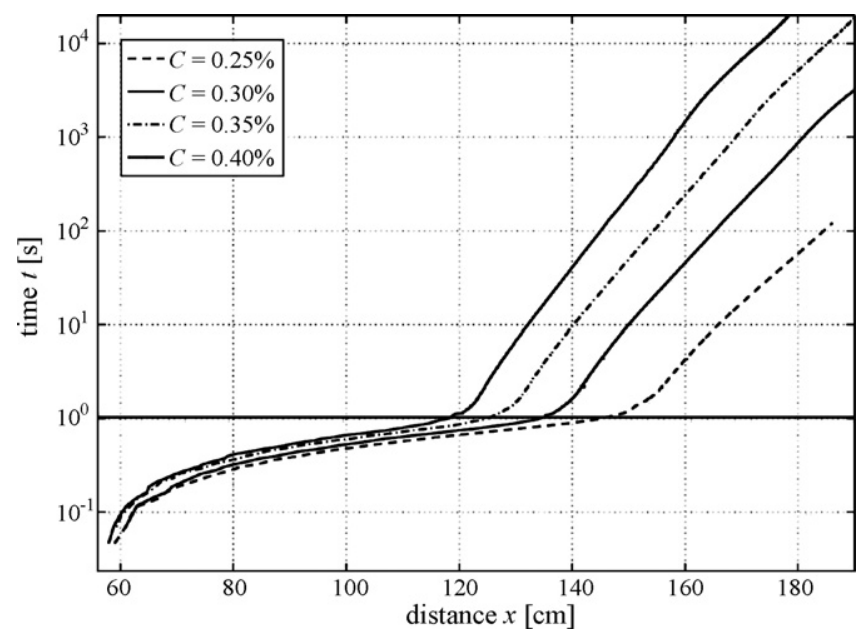

Fig. 16. Front position $x_{\mathrm{f}}$ in function of the time $t$ for a slope angle $\alpha=12^{\circ}$.

$0.8,2,20,200,2 \times 10^{3}$, and $2 \times 10^{4} \mathrm{~s}$ are reported in the upper half part; the left axis gives elevation $z$. The contact lines measured at the same time as the flow-depth profiles are plotted in the lower half part of the plot. The front position $x_{\mathrm{f}}$ is plotted as a function of time in a log-linear diagram; time $t$ is reported on the right axis. Note that $x=0$ corresponds to the rear end of the reservoir, while the 4 -cm-thick gate is located at $x=51-55 \mathrm{~cm}$. To guaranty an accurate measurement of the surge free-surface, the acquisition setup was positioned to record from $x=55 \mathrm{~cm}$ (the position of the dam-gate) to $x=190 \mathrm{~cm}$. The acquisition was stopped once the front position $x_{\mathrm{f}}$ had reached $190 \mathrm{~cm}$ or after $8 \mathrm{~h}$.

As expected, we observed that gels with the lowest Carbopol concentrations flowed faster and farther. Similarly, the steeper the inclination was, the faster the flows. Comparing the plots in Figs. 14 and 15 leads to further interesting observations:

- The typical duration $T_{\mathrm{i}}$ of the inertia-dominated regime was on the order of $1 \mathrm{~s}$. Taking a closer look at our data reveals a slight dependence of $T_{\mathrm{i}}$ on plane inclination. Strikingly enough, $T_{\mathrm{i}}$ seems to be independent of Carbopol concentration $C$, although the front position and velocity were influenced by $C$. A typical example is provided in Fig. 16, where we report the front position as a function of time for $\alpha=12^{\circ}$ and different $C$ values. For all concentrations, $T_{\mathrm{i}}$ was about $1 \mathrm{~s}$. The distance at which the transition from an inertial to a near-equilibrium regimes was observed depended on solid concentration: it increased from 120 to $145 \mathrm{~cm}$ when the concentration was increased from $0.25 \%$ to $0.4 \%$.

- During the inertial phase, the front velocity was nearly constant (e.g., see Fig. 12). This contrasts somehow with what we know of inertial flows. For inviscid fluids instantaneously released on a dry horizontal plane, dam-break theory predicts that the front velocity $u_{\mathrm{f}}$ does not vary with time, but solely with the initial flow depth $h_{0}: u_{\mathrm{f}}=\sqrt{2 g h_{0}}$ (Ritter's solution); for sloping beds, the front is continuously accelerating [54]. If we take the example of Fig. 12, the front velocity was about $70 \mathrm{~cm} / \mathrm{s}$, whereas an estimate of the front velocity for the Ritter solution is $u_{\mathrm{f}}=2.4 \mathrm{~m} / \mathrm{s}$, i.e. a factor of 3.5 higher than the velocity was observed. This clearly shows that even in the inertia-dominated regime, viscous dissipation played a non-negligible role.

- The shape of the free surface depended a great deal on slope, but weakly on Carbopol concentration. Fig. 17 reports the flow-depth profile together with the contact line for four different concentrations in Carbopol. All measurements were taken for a $12^{\circ}$ inclination and when the front reached the position $x_{\mathrm{f}}=138 \mathrm{~cm}$.

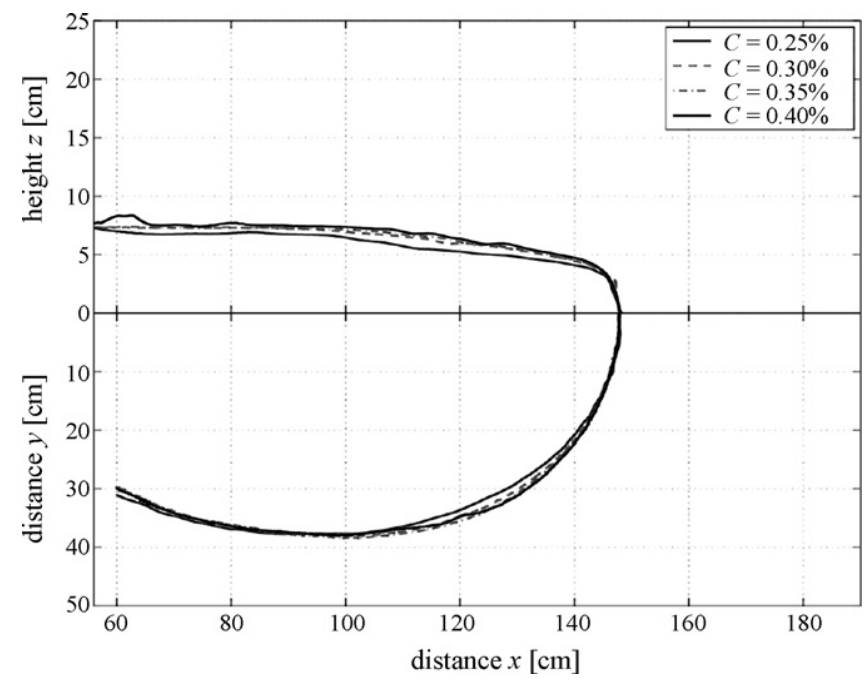

Fig. 17. Surge profile and contact line for a front position $x_{\mathrm{f}}=138 \mathrm{~cm}$ and $\alpha=12^{\circ}$.

Note that all profiles were quite similar. Interestingly enough, we can also point out that the flows were in a near-equilibrium regime except for the flow at $C=0.25 \%$ (which was still in an inertia-dominated regime). The maximum height difference was on the order of $6 \mathrm{~mm}$, while the maximum difference in the lateral spread was lower than $2 \mathrm{~cm}$. As shown in Fig. 18, where we plot the flow-depth profile and contact line for $\alpha=6^{\circ}$ and $18^{\circ}$ (other parameters being the same), slope has great influence on the free-surface shape.

- Lateral spreading mostly occurred during the inertial phase, as seen on each plot of Figs. 14 and 15. Plane inclination had little influence on lateral spreading, as illustrated in Fig. 19, where the contact lines are reported for different slopes $\alpha=0^{\circ}, 6^{\circ}, 12^{\circ}$, and $18^{\circ}$; the Carbopol concentration was the same $(C=0.3 \%)$ and the contact lines were recorded at the same time $t=1.6 \mathrm{~s}$.

- We did not observe any avalanching mass coming to a halt, even at shallow slope and with large-yield-stress fluids. This supports the theoretical analysis carried out by Matson and Hogg [33] and Balmforth et al. [10] for the dam-break problem on horizontal planes.

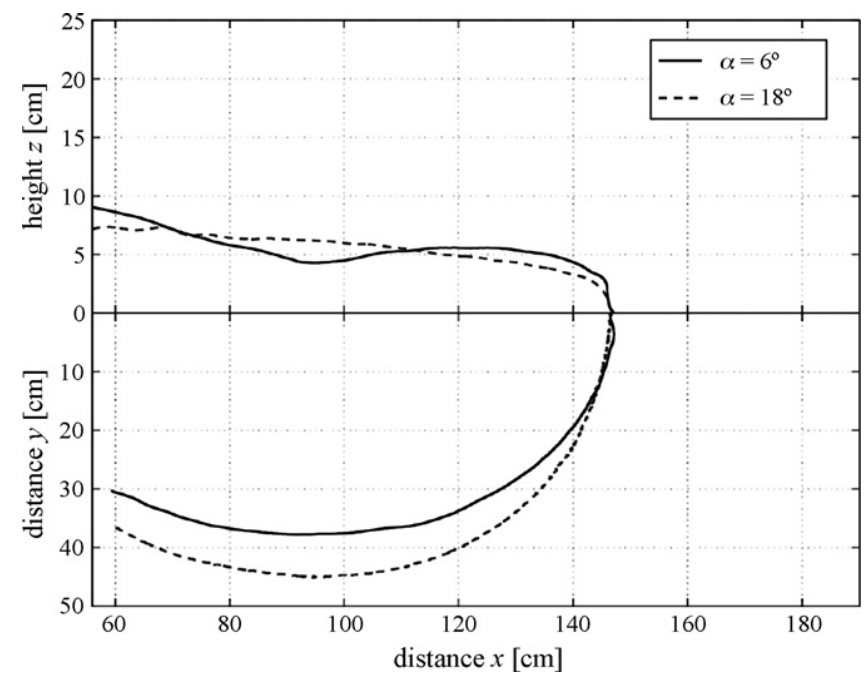

Fig. 18. Surge profile and contact line for a front position $x_{\mathrm{f}}=138 \mathrm{~cm}$ and $\alpha=12^{\circ}$. 


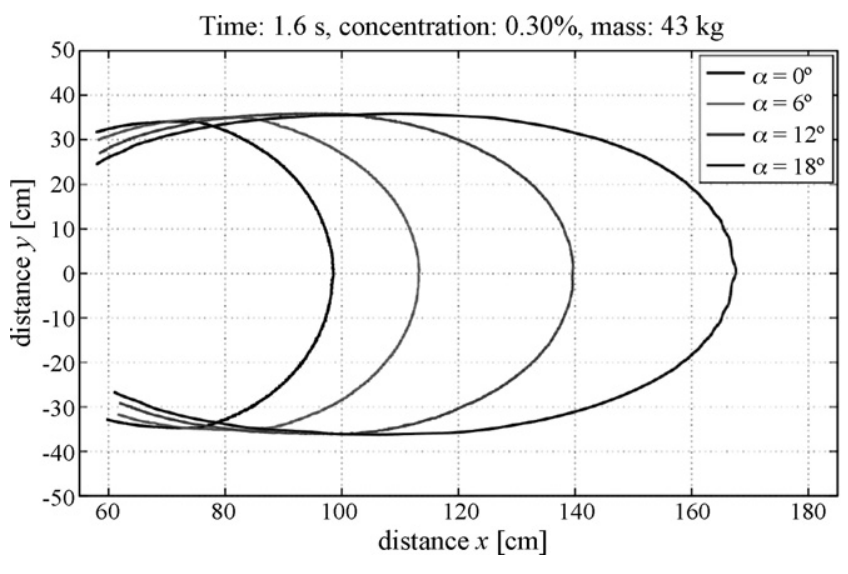

Fig. 19. Contact line at time $t=1.6 \mathrm{~s}$ for Carbopol at a concentration of $0.30 \%$ down inclined planes.

Another striking observation is that all front-position curves reported in Figs. 14 and 15 are $\mathrm{V}$-shaped. This shape similarity suggests that we can rescale the front position to obtain a crude, empirical scaling of $x_{\mathrm{f}}$ as a function of the flow parameters. By trial and error, we found that if we introduce the following dimension-
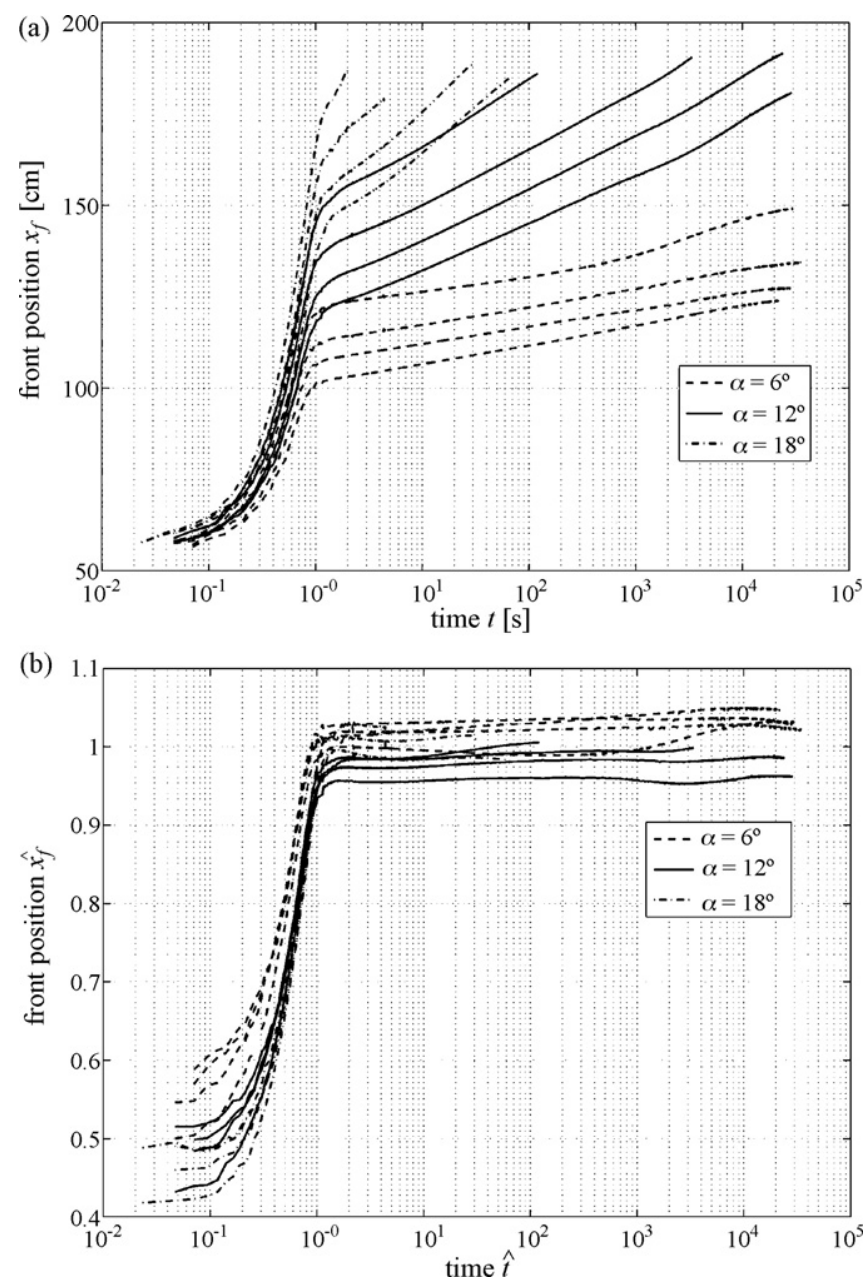

Fig. 20. (a) Front position $x_{\mathrm{f}}$ as a function of the time $t$ for all runs. (b) Scaled front position $\hat{x}_{\mathrm{f}}$ as a function of the time $\hat{t}$ for all runs.

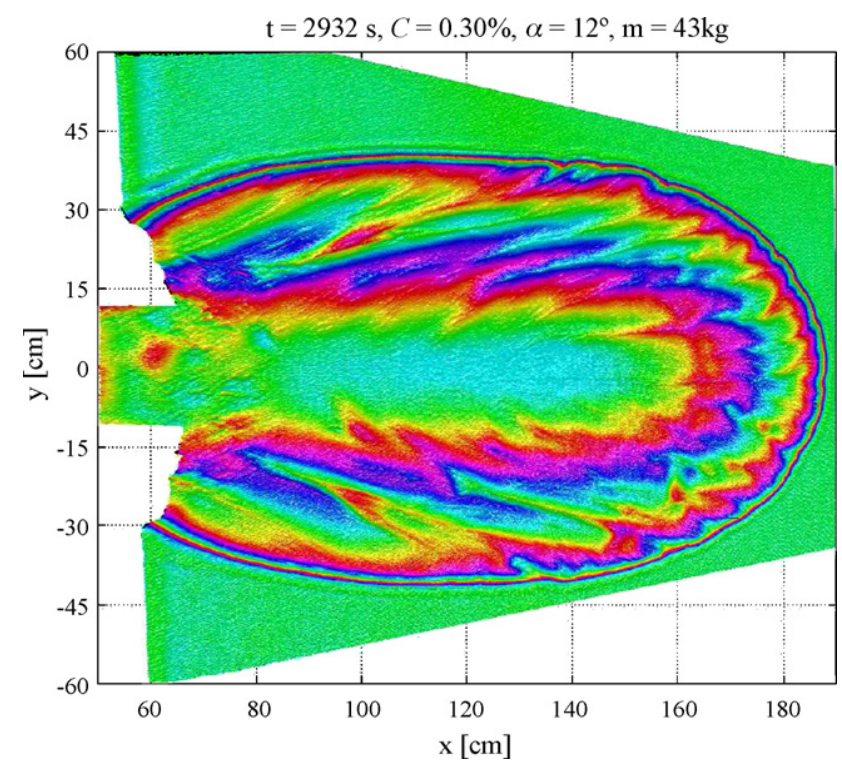

Fig. 21. Top view of surface structure formation at time $t=2932 \mathrm{~s}$ of a test with $C=0.25 \%$ and $\alpha=12^{\circ}$.

less variables:

$\hat{t}=\frac{t}{T_{\mathrm{i}}}$,

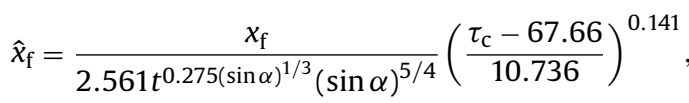

where $T_{\mathrm{i}}=1 \mathrm{~s}$ is the duration of the inertia-dominated regime, $t$ expressed in $\mathrm{s}, \alpha$ in ${ }^{\circ}, x_{\mathrm{f}}$ in $\mathrm{m}$, and $\tau_{\mathrm{c}}$ in Pa s, then the data nearly collapse on the same master curve, as shown in Fig. 20. The collapse is not perfect, indicating that this scaling is gross and holds only for the narrow range of flow conditions explored in our experiments. However, since similarity theory (or other theoretical arguments) does not provide any similarity form for the short- and longtime evolution of the front position (except for limiting cases), this empirical scaling provides some clues to appreciate the influence of the flow parameters on the bulk dynamics. In particular, it embodies a time dependency in the form $x_{\mathrm{f}} \propto t^{0.275(\sin \alpha)^{5 / 4}}$, which is markedly different from the long-time scaling observed for viscous fluids for which $x_{\mathrm{f}} \propto t^{1 / 3}$.

\subsection{Surface structure formation}

For all tests, surface structure formation was observed for the near-equilibrium regime (see Fig. 21). Here, 'surface structure formation' means that several channels formed at the margin of the avalanching mass. The higher the Carbopol concentration and the steeper the plane inclination were, the faster the channels appeared. The channels were almost symmetric about the centerline and aligned with the flow direction. These structures were not observed when the mass was confined in a flume [41]. This may be due to surface instabilities, but except for this scenario, we failed to find any reasonable explanation why regular patterns formed on the free surface.

\section{Conclusion}

To gain insight into the complex behavior of time-dependent, free-surface flows of viscoplastic materials, we built up an experimental setup, which makes it possible to carefully investigate the 
dam-break problem on horizontal and sloping beds in the laboratory. To track the free-surface evolution, we designed a novel imaging system made up of a high-speed digital camera coupled to a synchronized micro-mirror projector. The precision of our measurement system is on the order of $1 \mathrm{~mm}$ on a $1.4 \mathrm{~m} \times 1.4 \mathrm{~m}$ surface at a rate of $45 \mathrm{~Hz}$.

Here we focused on the behavior of a large mass of Carbopol suddenly released on a sloping plane. As a first approximation, Carbopol behaves like a Herschel-Bulkley fluid. Sixteen tests were carried out with a $43 \mathrm{~kg}$ mass of Carbopol at four different concentrations, $C=0.25 \%, 0.30 \%, 0.35 \%$, and $0.40 \%$. The plane inclination range from $0^{\circ}$ to $18^{\circ}$. The mass and the reservoir dimensions were kept constant. Comparing all runs, we observed that the behavior was nearly the same: at the very beginning, the mass accelerated vigorously on gate opening. We referred to this flow regime as the inertia-dominated regime. Although it had some similarities with fully inertial phases observed for inviscid and Newtonian fluids, we also observed substantial differences; in particular, the front velocity was constant and much lower than the front velocity given by the Ritter solution to the dam-break problem.

Strikingly enough, there was systematically a transition towards another flow regime at time $t=1 \mathrm{~s}$ whatever the slope or Carbopol concentration. The latter regime was referred to as the nearequilibrium regime since the flow-depth gradient being close to zero, the flow dynamics was dictated by the balance between gravitational and viscous forces, as in a steady uniform flow. Since we used fixed volumes of Carbopol, we could have expected to observe a run-out phase, where the mass came to a halt. Such a regime was never observed in our experiments. A remarkable feature of the near-equilibrium regime is that the front position varied as a power function of time over several decades. Another interesting observation concerns flow organization: lateral spreading occurred in the first instants, in the inertia-dominated regime, then became negligible. Because of yield stress, part of the fluid was abandoned at the lateral margins and formed levees that confined the yielded region, giving the appearance of a self-channelized flow. Surprisingly enough, the free surface became increasingly corrugated over time owing to "valley" formation in the streamwise direction.

Our results may be of significance to numericists and theoreticians investigating non-Newtonian flows in complex geometries. The present work may also interest geophysicists since viscoplastic models are commonly used to describe natural gravity-driven flows down steep slopes such as mud flows $[11,57,58]$, snow avalanches $[59,60]$, and lava flows [13].

\section{Acknowledgements}

The work presented here was supported by the Swiss National Science Foundation under grant number 200021-105193, the competence center in Mobile Information and Communication Systems (a center supported by the Swiss National Science Foundation under grant number 5005-67322, MICS project), the competence center in Environmental Sciences (TRAMM project), and specific funds provided by EPFL (vice-présidence à la recherche).

\section{References}

[1] N. Pashias, D. Boger, A fifty cent rheometer for yield stress measurement, J. Rheol. 40 (1996) 1179-1189.

[2] W. Schowalter, G. Christensen, Toward a rationalization of the slump test for fresh concrete: comparisons of calculations and experiments, J. Rheol. 42 (1999) 865-870.

[3] C. Ancey, H. Jorrot, Yield stress for particle suspensions within a clay dispersion, J. Rheol. 45 (2001) 297-319.

[4] A. Saak, H. Jennings, S. Shah, A generalized approach for the determination of yield stress by slump and slump flow, Cem. Concr. Res. 34 (2004) 363-371.
[5] N. Roussel, P. Coussot, "Fifty-cent rheometer" for yield stress measurements: from slump to spreading flow, J. Rheol. 49 (2005) 705-718.

[6] J.-M. Piau, Consistometry slump and spreading tests: practical comments, J. Non-Newtonian Fluid Mech. 135 (2006) 177-178.

[7] P. Perona, Bostwick degree and rheological properties: an up-do-date viewpoint, Appl. Rheol. 15 (2005) 218-229.

[8] J.-M. Piau, Axisymmetric slump and spreading of cohesive plastic soft materials: a yield stress measurement by consisto-rheometry, J. Rheol. 49 (2005) 1253-1276.

[9] R. Milczarek, K. McCarthy, Relationship between the Bostwick measurement and fluid properties, J. Texture Stud. 37 (2006) 640-654.

[10] N. Balmforth, R. Craster, P. Perona, A. Rust, R. Sassi, Viscoplastic dam breaks and the Bostwick consistometer, J. Non-Newtonian Fluid Mech. 142 (2007) 63-78.

[11] P. Coussot, Mudflow Rheology and Dynamics, Balkema, Rotterdam, 1997.

[12] C. Ancey, Plasticity and geophysical flows: a review, J. Non-Newtonian Fluid Mech. 142 (2007) 4-35.

[13] R. Griffiths, The dynamics of lava flows, Annu. Rev. Fluid Mech. 32 (2000) 477-518.

[14] P. Smith, A similarity solution for slow viscous flow down an inclined channel, J. Fluid Mech. 58 (1973) 275-288.

[15] H. Huppert, The propagation of two-dimensional and axisymetric viscous gravity currents over a rigid horizontal surface, J. Fluid Mech. 121 (1982) 43-58.

[16] J. Lister, Viscous flows down an inclined plane from point and line sources, J. Fluid Mech. 242 (1992) 631-653.

[17] J. Simpson, Gravity Currents in the Environment and the Laboratory, Cambridge University Press, Cambridge, 1997.

[18] K. Liu, C. Mei, Slow spreading of a sheet of Bingham fluid on an inclined plane, J. Fluid Mech. 207 (1990) 505-529.

[19] C. Mei, M. Yuhi, Slow flow of a Bingham fluid in a shallow channel of finite width, J. Fluid Mech. 431 (2001) 135-159.

[20] N. Balmforth, A. Burbridge, R. Craster, Viscoplastic models of isothermal lava domes, J. Fluid Mech. 403 (2000) 37-65.

[21] N. Balmforth, R. Craster, R. Sassi, Shallow viscoplastic flow on an inclined plane, J. Fluid Mech. 470 (2002) 1-29.

[22] N. Balmforth, R. Craster, R. Sassi, Dynamics of cooling viscoplastic domes, J. Fluid Mech. 499 (2004) 149-182.

[23] N. Balmforth, R. Craster, A. Rust, R. Sassi, Viscoplastic flow over an inclined surface, J. Non-Newtonian Fluid Mech. 142 (2007) 219-243.

[24] S. Wilson, S. Burgess, The steady, spreading flow of a rivulet of mud, J. NonNewtonian Fluid Mech. 79 (1998) 77-85.

[25] S. Wilson, B. Duffy, R. Hunt, A slender rivulet of a powder-law fluid driven by either gravity or a constant shear stress at the free surface, Quart. J. Mech. Appl. Math. 55 (2002) 385-408.

[26] P. Coussot, S. Proust, Slow, unconfined spreading of a mudflow, J. Geophys. Res. B101 (1996) 25217-25229.

[27] P. Coussot, S. Proust, C. Ancey, Rheological interpretation of deposits of yield stress fluids, J. Non-Newtonian Fluid Mech. 66 (1996) 55-70.

[28] D. Osmond, R. Griffiths, The static shape of yield strength fluids slowly emplaced on slopes, J. Geophys. Res. B 106 (2001) 16241-16250.

[29] M. Yuhi, C. Mei, Slow spreading of fluid mud over a conical surface, J. Fluid Mech. 519 (2004) 337-358.

[30] X. Huang, M. Garcìa, A perturbation solution for Bingham-plastic mudflows, J. Hydraul. Eng. 123 (1997) 986-994.

[31] X. Huang, M. Garcìa, A Herschel-Bulkley model for mud flow down a slope, J. Fluid Mech. 374 (1998) 305-333.

[32] H. Chanson, S. Jarny, P. Coussot, Dam break wave of thixotropic fluid, J. Hydraul. Eng. 132 (2006) 280-293.

[33] G. Matson, A. Hogg, Two-dimensional dam break flows of Herschel-Bulkley fluids: the approach to the arrested state, J. Non-Newtonian Fluid Mech. 142 (2007) 79-94.

[34] A. Hogg, D. Pritchard, The effects of hydraulic resistance on dam-break and other shallow inertial flows, J. Fluid Mech. 501 (2004) 179-212.

[35] D. Laigle, A.-F. Hector, J. Hübl, D. Rickenmann, Comparison of numerical simulation of muddy debris flow spreading to records of real events, in: D. Rickenmann, C. Chen (Eds.), Debris Flow Hazard and Mitigation, ASCE, Davos, 2003.

[36] M. Pastor, M. Quecedo, E. González, M. Herreros, J. Fernández, P. Mira, Simple approximation to bottom friction for Bingham fluid depth integrated models, J. Hydraul. Eng. 130 (2004) 149-155.

[37] A. Siviglia, A. Cantelli, Effect of bottom curvature on mudflow dynamics: theory and experiments, Water Resour. Res. 41 (2005) W11423.

[38] K. Debiane, Hydraulique des écoulements laminaires à surface libre dans un canal pour des milieux visqueux ou viscoplastiques, Ph.D. thesis, Université Joseph Fourier Grenoble, 2000.

[39] P. Stansby, A. Chegini, T. Barnes, The initial stages of dam-break flow, J. Fluid Mech. 370 (1998) 203-220.

[40] S. Cochard, C. Ancey, Tracking the free surface of time-dependent flows: image processing for the dam-break problem, Exper. Fluids 44 (2008) 59-71.

[41] C. Ancey, S. Cochard, The dam-break problem for Herschel-Bulkley viscoplastic fluids down steep flumes, J. Non-Newtonian Fluid Mech 158 (2009) 18-35.

[42] S. Cochard, Measurements of time-dependent free-surface viscoplastic flows down steep slopes, Ph.D. thesis, Ecole Polytechnique Fédérale de Lausanne, 2007. 
[43] H. Barnes, K. Walters, The yield stress myth? Rheol. Acta 24 (1985) 324-326.

[44] P. Coussot, Q. Nguyen, H. Huynh, D. Bonn, Avalanche behavior in yield stress fluids, Phys. Rev. Lett. 88 (2002) 175501.

[45] P. Møller, J. Mewis, D. Bonn, Yield stress and thixotropy: on the difficulty of measuring yield stresses in practice, Soft Matter 2 (2006) 274-283.

[46] J.-M. Piau, Carbopol gels: elastoviscoplastic and slippery glasses made of individual swollen sponges meso- and macroscopic properties, constitutive equations and scaling laws, J. Fluid Mech. 144 (1) (2007) 1-29.

[47] Y. Yeow, W. Ko, P. Tang, Solving the inverse problem of Couette viscometry by Tikhonov regularization, J. Rheol. 44 (2000) 1335-1351.

[48] C. Ancey, Solving the Couette inverse problem by using a waveletvaguelette decomposition, J. Rheol. 49 (2005) 441-460.

[49] H.A. Barnes, Thixotropy-a review, J. Non-Newtonian Fluid Mech. 70 (1997) $1-33$.

[50] G. Roberts, H. Barnes, New measurements of the flow-curves for Carbopol dispersions without slip artefacts, Rheol. Acta 40 (2001) 499-503.
[51] H. Barnes, Q. Nguyen, Rotating vane rheometry-a review, J. Non-Newtonian Fluid Mech. 98 (2001) 1-14.

[52] C.-S. Wu, Y. Kwak, Characterization of microgels by Brookfield viscometry with cylindrical, t-bar, and flags impeller spindles, J. Appl. Polym. Sci. 71 (1999) 67-74.

[53] C. Wu, G. Huang, Y. Zheng, Theoretical solution of dam-break shock wave, J. Hydraul. Eng. 125 (1999) 1210-1220.

[54] C. Ancey, M. Rentschler, R. Iverson, R.P. Denlinger, An exact solution for ideal dam-break floods on steep slopes, Water Resour. Res. 44 (2008)W01430.

[57] A. Johnson, J. Rodine, Debris flow, in: D. Brunsden, D. Prior (Eds.), Slope Instability, John Wiley \& Sons, Chichester, 1984, pp. 257-362.

[58] Z. Wan, Z. Wang, Hypercontrated Flow, Balkema, Rotterdam, 1994.

[59] J. Dent, T. Lang, Experiments on the mechanics of flowing snow, Cold Regions Sci. Technol. 5 (1982) 243-248.

[60] C. Ancey, Snow avalanches, in: N. Balmforth, A. Provenzale (Eds.), Geomorphological Fluid Mechanics: Selected Topics in Geological and Geomorphological Fluid Mechanics, Springer, Berlin, 2001, pp. 319-338. 